\title{
The Impact of Adopting ERP on Key Performance Indicator by the Mediation Effect of Critical Success Factors and Performance Indicators in Automobile Ancillary Industries
}

\author{
S. Edmund Christophe
}

\begin{abstract}
To meet the very high expectation of the customer in the competitive and luxury Automotive global market segment, the organization requires flexibility, business integration and automation of the business process which will reduce the cost and time in various business processes. An Enterprise Resource Planning (ERP) system plays a major role in improving the performance of the supply chain. Some studies expressed that Organizations, which have good ERP systems, generate higher profit because of reduction in Cost and Time. However, there is a lack of scientific research carried out that effective ERP Implementation leads to better business performance which helps to attain the Key Performance Indicator set by the organization. In this paper, we attempt to determine how the companies that have adopted ERP Systems in Automobile Auxiliary Industries have improved their business performance, by evaluating and analyzing the association between the performance indicators Time Reduction and Cost Reduction using Structural Equation Modeling (SEM). The findings of the SEM research stated that, companies that adopted ERP system improves their business performance Indicator, particularly in relation to Key Performance Indicator. Furthermore, we found that the impact of ERP Systems Performance study absolute fit indices fits the sample data and reveals that the proposed model has the acceptable fit, by way of satisfying the recommended values.
\end{abstract}

Keywords--- Enterprise Resource Planning, Automotive Ancillary Industry, Structural Equation Model.

\section{INTRODUCTION}

The world today has become extremely competitive. In fact, volatile changes in the demand increase more complex and competitive in the global Automotive market. Business in this information age must ready to accept competitive and customer focused in order to survive, thrive and beat the competition. All the automotive organizations have certain objectives and goals to achieve. To attain the objective and goal of the organization, all the business departments need to work towards the common goal to succeed. But each department in the organization has their own goals and procedure to act in terms of their Key Performance Indicator. These departmental objectives can sometimes be conflicting. For example, production planning department, might want to reduce the inventory, but production folks want to have more stocks. The success of the organization is resolving this kind of conflicts between the business functions and department. Each and employee in the organization should know what is their counterpart is doing

Revised Manuscript Received on July 10, 2019.

S. Edmund Christophe, Associate Professor and Dean of Academic Affairs, Emirates College for Management and Information Technology (ECMIT), Dubai, UAE. (e-mail: edmundchristo@gmail.com) and what is the impact of their actions and decision to another department. So, Information Technology (IT) has a major role to play, both the organization and business function levels planning and decision making. At the organization level IT assist the top-level executives and managers to achieve their objective and strategies of the organization by developing systems and procedure. At the department level IT assist smooth flow of information across the departments by adapting the best business practices.

An Enterprise Resource Planning (ERP) is the latest Information Technology solution that integrates entire business functions in the organization or within the organization into a single system with a single or shared database. These ERP software packages can be customized according to the specific needs of the organization. ERP Systems give huge impact on the organization business and information technology world.

The following three major benefits in supply chain by adapting ERP systems

- Business process automation, control and execution.

- Timely access of management information from anywhere at any time

- Well Improvement supply chain Management functions use of Supplier Relationship Management (SRM)

\section{REVIEW OF LITERATURE}

Automotive Industries is a vital industry in manufacturing sector that comprise continuous movement of material from the raw material, intermediate material or finished product that are procured, transformed, stored and sold. Manufacturing costs are rising. Demands are dynamically changing. Business globalization changing the competitor, manufacturers, distributors, dealers and suppliers landscape. They are responding to these challenges by looking the demand and supply of the current trend. ERP extensively helpful in active supply chains in automotive logistics to manage, monitor and reduce the cost. It clarifies the business processes, and improves delivery accuracy to the customer (1).

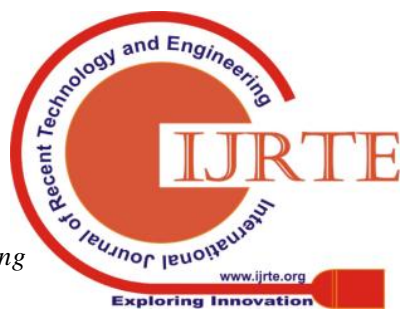


The Man, Machine, money, method are integrated in ERP. ERP helps the organization to build a supply chain in such a way that easier to manage, anticipate and respond quickly on dynamic changes in the market conditions (2). It also makes the organization more competitive, like service, productivity and innovation.

"A supply chain is a process or system which organizations, people, technology, process, activities, information and resources involved in moving a product or service from supplier to customer in various form of materials", according to the definition of Wikipedia [3]. In Supply chain process, the coordination and integration of various business activities in an organization are happening from the procurement of raw materials from the supplier manufacturing intermediate and finished product and delivery of finished products to the customer. The Enterprise Resource planning system is an optimizer which gathers and process necessary information among the supply chain operations and capacities from supply chain members to reduce the inventory and cost.

Automobile industries in the worldwide are looking to ERP systems to streamline their businesses and shift from manual system to automatic information management systems. A holistic ERP system can replace multiple databases with a single and centralized data source, with information relating to people, process, products, services, customers and suppliers accessible by anyone in a company. These interconnected and robust systems can be powerful, integrating information across an organization or different organization [4], In order to better integrate and coordinate procurement, manufacturing, sub contracting functions between or within the organizations.

Automobile industries need to implement ERP system as a solution. By implementing ERP systems, it attain a number of benefits include coordination of enterprise-wide operations between or within the organization, inventory control functionality for storage product, rapid real-time data sharing and accessing the information at any time anywhere, customizable interfaces, and scalable for growing business [5].Therefore; automobile industry has been selected for this study in order to analyze the performance measure. The result of the study provides a clear-cut idea about the different business process and how they integrated with different department/modules in area ERP and their benefits of implementing them.

ERP system provides a number of advantages for firms to improve the organization performance. Based on Information perspective, ERP system adoption can improve the interaction between the business functions and the information is more reachable. ERP systems have more advantages in information quality and the integration of business processes and operations, but it does not decrease the information technology costs [6]. Based on Shang and Seddon [6], ERP systems have several benefits, which can be attained by organization. These benefits are differed into five major benefits which include strategic benefits, operational benefits, managerial benefits, IT infrastructure design and organizational benefits. The research contribution from Shang and Seddon is comparable to Garg and Venkitakrishnan [7], who identified the intangible benefits of ERP system implementation, They are better

customer and share holders satisfaction, improve vendor performance ratings, increase flexibility of accessing system, reduces quality costs, improve resource utilization , improve information accuracy which will give improved decision making capability. Olhager and Selldin [8] identified tangible benefits of ERP system, include reduction of lead time, on-time shipments to the customer, double business, reduce cycle time, and work in progress.

A successfully ERP implemented system has the advantages of reducing the cost and quality of the product [9]. It gives the benefits to its customers on purchase products or goods at low prices and shares the information of production status in real time [10]. The benefit of ERP systems is highly dependent on the success of its implementation. In order to get the best ERP implementation system must be managed as a program of wide ranging organizational change not as a software installation [11]. Many business organizations adopted ERP systems to attain the benefits they wanted [12]. After successfully ERP implementation, companies can set up standards in financial management transactions and operating procedures on managing real time inventory systems [13]. The operational benefits of ERP software include efficiency measures of reduced turn-cycles in the elaboration of reports, swiftness in data sharing, and improvements in data quality due to reduced redundancies. ERP is tied to reduce the cost which leads to improve performances in the supply-chain efficiency, faster financial reporting, more visible data and a higher capacity for producing high-quality analytics and a process-centered mentality [16]. Additionally, ERP is noted for other efficiencies, such as reduce inventory cost, decrease labor costs and faster financial closings. Managerial outcomes are derived from the improved decision making of managers, who can access comprehensive, up-to-date reporting mechanisms and drill down capabilities using ERP [15]. Managerial expectations include better resource management and better performance control [15]. In terms of the strategic dimension, the primary expectations of ERP software are that it support business growth through information sharing with suppliers, customers and other business alliances, reduce costs under a cost-leadership strategy or promote differentiation and increased sales through customer relationship modules and e-commerce capabilities. Qu et al. [14] suggest that an organization's long-term plans and decisions should be driven by the company's internal and industry dynamics that affect their strategic policies and implementation

\section{Problem Statement}

Organizations are focusing on increasing profit by reducing various costs in their supply chain activity and reducing the time during the Supply Chain. An Enterprise Resource Planning (ERP) system plays a major role in improving the supply chain activities, competiveness, productivity and profit across the organization by proper planning and scheduling execution of activities. 
To meet the very high expectation of the customer in the competitive and luxury global Automotive market segment, the organization requires flexibility, business integration and automation of the business process which will reduce the cost in various business processes. Planning to implement ERP systems requires an integrated approach to meet the requirement of the various business processes. The major challenge in the organization is segregation of the various business processes and Performance Indicators of various cost and time involved on the process. In some of the organization even though they have proper planning and ERP implementation strategy, they are unable to achieve the profit predicted. The cost of an ERP implementation project is very high and Time taken to deliver the product is high. it is essential for every organization to implement the ERP successfully to get the organization goals. Therefore, a detailed study about the business process and their benefits will improve the business performance, optimization and profit of the organization.

\section{Objectives of the study}

The objectives of this study are as follows:

- To investigate the various Performance Indicator in cost involves during the supply chain process of Automobile Ancillary Industry and analyze the impact of CSFs of the ERP implementation.

- To investigate the various Performance Indicator in Time involves during the supply chain process of Automobile Ancillary Industry and analyze the impact of CSFs of the ERP implementation.

- To analyze the Key Performance Indicators [KPIs] specific to the automobile ancillary industry and examine the effect Performance Indicator Cost and Time after the ERP Implementation

- To evaluate whether all the measures fit the recommended value, indicating a good fit of the structural model for the collected data

Conceptual Structural Equation Model (SEM) and Hypotheses

For analyzing both the measurement and structural models of this study, the structural equation modeling (SEM) method was employed as it was capable of allowing the incorporation of both unobserved (i.e. latent) and observed variables in the same model, and being able to handle errors of measurement within exogenous variables in a better manner. Additionally, SEM is able to process multiple dependent variables, which is not feasible in a traditional regression analysis method (Chin, Marcolin, \& Newsted, 2003; Gefen,Straub, \& Boudreau, 2000).Two diverse methodological approaches are proposed to calculate SEM.

The variables used in this structural equation model are:

Observed, endogenous variables

1. Cost Reduction

2. Time Reduction

3. Key Performance Indicator

Observed, exogenous variables

1. Training and Development

2. Top management Support

\section{Project Management}

Unobserved, exogenous variables

1. e1: Error term for Cost Reduction

2. e2: Error term for Time Reduction

3. e3: Error term for Key Performance Indicator

Hence number of variable in the SEM is

Number of variables in this model: 9

Number of observed variables:

Number of unobserved variables:

Number of exogenous variables:

Number of endogenous variables:

Figure 1 shows the conceptual Structural Equation model of this research where CSFs Training and development, Top Management Support and commitment and project management are considered as independent variables which are influencing on the dependent variables Reduction in cost and Reduction in Time which will decide the Key Performance Indicator set by the Organizations.



Fig. 1: Structural Equation Model (SEM) based on Standardized Coefficient on ERP Performance

Based on the objectives the following hypotheses have been framed and tested. For the purpose of testing the model fit, null hypothesis and alternative hypothesis are framed as shown below

Table 1: Shows the Hypothesis for this SEM Model

\begin{tabular}{|c|c|}
\hline Null Hypothesis & Alternate Hypothesis \\
\hline $\begin{array}{l}\mathrm{H}_{1} 0 \text { : There is no association } \\
\text { between Critical Success Factors } \\
\text { and Performance Indicator Cost in } \\
\text { Automobile Ancillary Industries } \\
\text { ERP Implementation }\end{array}$ & $\begin{array}{l}\mathrm{H}_{1} \text { a: There is an association } \\
\text { between Critical Success Factors } \\
\text { and Performance Indicator Cost in } \\
\text { Automobile Ancillary Industries } \\
\text { ERP Implementation }\end{array}$ \\
\hline $\begin{array}{l}\mathrm{H}_{2} 0 \text { : There is no association } \\
\text { between Critical Success Factors } \\
\text { and Performance Indicator Time in } \\
\text { Automobile Ancillary Industries } \\
\text { ERP Implementation }\end{array}$ & $\begin{array}{l}\mathrm{H}_{2} \mathrm{a} \text { : There is an association } \\
\text { between Critical Success Factors } \\
\text { and Performance Indicator Time in } \\
\text { Automobile Ancillary Industries } \\
\text { ERP Implementation }\end{array}$ \\
\hline $\begin{array}{l}\mathrm{H}_{3} \mathrm{O} \text { : There is no significant } \\
\text { difference KPIs specific to the } \\
\text { automobile ancillary industry and } \\
\text { Performance Indicator Cost and } \\
\text { Time after ERP Implementation. }\end{array}$ & $\begin{array}{l}\mathrm{H}_{3} \mathrm{a} \text { : There is an significant } \\
\text { difference KPIs specific to the } \\
\text { automobile ancillary industry and } \\
\text { Performance Indicator Cost and } \\
\text { Time after ERP Implementation. }\end{array}$ \\
\hline $\begin{array}{l}\mathrm{H}_{4} 0 \text { : The hypothesized model does } \\
\text { not have a good fit }\end{array}$ & $\begin{array}{l}\mathrm{H}_{4} \mathrm{a} \text { : The hypothesized model has a } \\
\text { good fit. }\end{array}$ \\
\hline
\end{tabular}




\section{RESEARCH METHODOLOGY}

\section{Survey Design}

The survey instrument was designed and used for data collection for this study This study used both primary and secondary data. Secondary data was collected from websites, thesis, various journals and books. The primary data is collected for the performance measures CSFs, Cost and Time and KPIs data collected from the from the Business Process owners[BPOs], Top level Management and middle level managers and various business users involved in the ERP Implementation \& Usage. A five-point scale (5 indicating strongly agree and 1 indicating strongly disagree) was used in preference to a seven-point scale to increase the sensitivity of the measure.

\section{Data Collection and Sampling Method}

Data were collected from 150 respondents who are all having very good knowledge in business process and ERP usage in Automobile ancillary industries who are all manufacturing. The data is collected from Top 20 component manufacturing organization in Tamilnadu with different manufacturing Parts. Like Drive and Transmission parts, suspension and braking, Engine and Engines parts , Electrical Parts and Glass Parts .Multistage Random Sampling method used to collect the data from 1100 ERP users.

\section{DATA ANALYSIS AND HYPOTHESIS TESTING}

Collected data were analyzed with the help of software package SPSS and analysis of moment structure (AMOS) 20.0. Statistical techniques like descriptive analysis, reliability analysis, exploratory factor analysis, confirmatory factor analysis was used to evaluate the service quality. Structural equation modeling (SEM) was used for data analysis.

\section{DISCUSSION \& RESULTS}

Table 2: Shows Variables in the Structural Equation Model Analysis

\begin{tabular}{|c|c|c|c|c|c|c|c|}
\hline \multicolumn{3}{|l|}{ Variables } & $\begin{array}{l}\text { Unstandardised co- } \\
\text { efficient } \\
\text { (B) }\end{array}$ & $\begin{array}{l}\text { S.E } \\
\text { of B }\end{array}$ & $\begin{array}{l}\text { Standardised co- } \\
\text { efficent } \\
\text { (Beta) }\end{array}$ & $\begin{array}{l}T \\
\text { value }\end{array}$ & $P$ value \\
\hline Cost & $<--$ & $\begin{array}{l}\text { Training and } \\
\text { Development }\end{array}$ & 2.467 & 0.309 & 0.498 & 7.982 & $<0.001 * *$ \\
\hline Time & <--- & $\begin{array}{l}\text { Training and } \\
\text { Development }\end{array}$ & 1.041 & 0.335 & 0.224 & 3.108 & $0.002 *$ \\
\hline Cost & <--- & $\begin{array}{l}\text { Top management } \\
\text { Support }\end{array}$ & 0.447 & 0.136 & 0.169 & 3.301 & $<0.001 * *$ \\
\hline Time & $<--$ & $\begin{array}{l}\text { Top management } \\
\text { Support }\end{array}$ & 0.673 & 0.147 & 0.270 & 4.583 & $<0.001 * *$ \\
\hline Cost & $<--$ & Project Management & 1.319 & 0.218 & 0.326 & 6.041 & $<0.001 * *$ \\
\hline Time & $<--$ & Project Management & 1.829 & 0.237 & 0.480 & 7.732 & $<0.001 * *$ \\
\hline $\begin{array}{l}\text { Key Performance } \\
\text { Indicator }\end{array}$ & $<--$ & Cost & 0.614 & 0.057 & 0.644 & 10.828 & $<0.001 * *$ \\
\hline $\begin{array}{l}\text { Key Performance } \\
\text { Indicator }\end{array}$ & $\begin{array}{l}<-- \\
\end{array}$ & Time & 0.319 & 0.060 & 0.315 & 5.287 & $<0.001 * *$ \\
\hline
\end{tabular}

Note: $* *$ denotes significant at $1 \%$ level

* denotes significant at $5 \%$ level

From the above table,

Unstandardized coefficient of Training and Development on Cost Reduction is 2.467 represents the partial effect of Training and Development on Cost Reduction, holding the other path variables as constant. The estimated positive sign implies that such effect is positive that Cost Reduction would increase by 2.467 for every unit increase in Training and Development and this coefficient value is significant at $1 \%$ level.

Unstandardized coefficient of Training and Development on Time Reduction is 1.041represents the partial effect of Training and Development on Time Reduction, holding the other path variables as constant. The estimated positive sign implies that such effect is positive that Time Reduction would increase by 1.041 for every unit increase in Training and Development and this coefficient value is significant at $5 \%$ level.

Unstandardized coefficient of Top Management Support on Cost Reduction is 0.447 represents the partial effect of Top Management Support on Cost Reduction, holding the other path variables as constant. The estimated positive sign implies that such effect is positive that Cost Reduction would increase by 0.447 for every unit increase in Top Management Support and this coefficient value is significant at $1 \%$ level.

Unstandardized coefficient of Top Management Support on Time Reduction is 0.673 represents the partial effect of Top Management Support on Time Reduction, holding the other path variables as constant. The estimated positive sign implies that such effect is positive that Time Reduction would increase by 0.673 for every unit increase in Top Management Support and this coefficient value is significant at $1 \%$ level.

Unstandardized coefficient of Project Management on Cost Reduction is 1.319 represents the partial effect of Project Management on Cost Reduction, holding the other path variables as constant. 
The estimated positive sign implies that such effect is positive that Cost Reduction would increase by 1.319 for every unit increase in Project Management and this coefficient value is significant at $1 \%$ level.

Unstandardized coefficient of Project Management on Time Reduction is 1.829 represents the partial effect of Project Management on Time Reduction, holding the other path variables as constant. The estimated positive sign implies that such effect is positive that Time Reduction would increase by 1.829 for every unit increase in Project Management and this coefficient value is significant at $1 \%$ level.

Unstandardized coefficient of Key Cost Reduction on Key Performance Indicator is 0.614 represents the partial effect of Cost Reduction on Key Performance Indicator, holding the other path variables as constant. The estimated positive sign implies that such effect is positive that Key Performance Indicator would increase by 0.614 for every unit increase in Cost Reduction and this coefficient value is significant at $1 \%$ level.

Unstandardized coefficient of Time Reduction on Key Performance Indicator is 0.319 represents the partial effect of Time Reduction on Key Performance Indicator, holding the other path variables as constant. The estimated positive sign implies that such effect is positive that Key Performance Indicator would increase by 0.319 for every unit increase in Time Reduction and this coefficient value is significant at $1 \%$ level.

Based on Standardized coefficient, Cost on Key Performance Indicator (0.644) is most influencing path in this SEM model, followed by Training and Development on Cost Reduction (0.498), Project Management on Time Reduction (0.480) and so on

Table 3: Model fit summary of Structural Equation Model

\begin{tabular}{|l|l|l|}
\hline Indices & Value & Suggested value \\
\hline Chi-square value & 9.645 & - \\
\hline DF & 3 & - \\
\hline P value & 0.102 & $>0.05$ ( Hair et al., 1998) \\
\hline Chi-square value/DF & 3.215 & $<5.00$ ( Hair et al., 1998) \\
\hline GFI & 0.937 & $>0.90$ (Hu and Bentler, 1999) \\
\hline AGFI & 0.918 & $>0.90$ ( Hair et al. 2006) \\
\hline NFI & 0.969 & $>0.90($ Hu and Bentler, 1999) \\
\hline CFI & 0.972 & $>0.90$ (Daire et al., 2008) \\
\hline RMR & 0.026 & $<0.08$ ( Hair et al. 2006) \\
\hline RMSEA & 0.062 & $<0.08$ (Hair et al. 2006) \\
\hline
\end{tabular}

From the above table, it is found that the calculated $\mathrm{P}$ value is 0.102 which is greater than 0.05 which indicates perfectly fit. Here Goodness of Fit Index (GFI) value (0.937) and Adjusted Goodness of Fit Index (AGFI) value $(0.918)$ is greater than 0.9 which represent it is a good fit. The calculated Normed Fit Index (NFI) value (0.969) and Comparative Fit Index (CFI) value (0.972) indicates that it is a perfectly fit and also it is found that Root Mean square Residuals (RMR) and Root Mean Square Error of Approximation (RMSEA) value is 0.062 which is less than 0.08 which indicated it is perfectly fit.

\section{CONCLUSION}

After testing the hypothetical path by the structural equation modeling results reveal that CSFs Training and Development. Advanced Hardware and Software used, Project management support and change Management and Top Management Support and Commitment on Reduction in Cost and Reduction in time in SCM Process which helps to achieve the KPIs set by the Organization.

The Implications of Research for Automobile Ancillary Industries are as follows.

- Many executives or directors of Automobile Ancillary Industries were suspicious about achieving KPIs benefits of modern information systems like ERP. Findings through systematic study using structural equation modeling indicate that Indian Automobile ancillary industries with ERP systems are getting of Reduction in Cost and Reduction in time in SCM Process which helps to achieve the KPIs set by the Organization to remain more competitive in this knowledge based economy. This will encourage such type of implementations in Indian Automobile Industry.

- This research work develops action plan for switching over of organization from legacy system to low cost ERP solutions like cloud based system, open source ERP systems for Automobile Ancillary Industries in order to face the global challenges.

In knowledge based economy, Indian Automobile Ancillary Industries have challenges to provide high quality product at low cost, to remain more competitive in world. Automobile Ancillary Industries represent the spinal cord of Indian economy. To improve productivity and overall business performance, Enterprise Resource Planning (ERP) is one of the best solutions for the Automobile Ancillary Industries in order to face the global challenges.

This study expected to meet following objectives

- Investigated the various Performance Indicator in cost involves during the supply chain process of Automobile Ancillary Industry and analyze the impact of CSFs of the ERP implementation.

- Investigated the various Performance Indicator in Time involves during the supply chain process of Automobile Ancillary Industry and analyze the impact of CSFs of the ERP implementation.

- Analyzed the Key Performance Indicators [KPIs] specific to the automobile ancillary industry and examine the effect Performance Indicator Cost and Time after the ERP Implementation

- Evaluated and all the measures fit the recommended value, indicating a good fit of the structural model for the collected data

\section{REFERENCES}

1. Enterprise Resource planning - Alexis Leon

2. Monk, Wager, Concepts in enterprise resource planning third edition, Course Technology learning 2009. 
3. http://en.wikipedia.org/wiki/Supply_chain

4. Deschamps, M.J. Enterprise Resource Planning - the benefits, Information on http://www.justfood.com/management-briefing/enterpriseresource

5. Syspro. Astrapak Standardizes on SYSPRO to Accommodate Expansion, Syspro Case Study: Astrapak. 2005.

6. Shang, S., Seddon, P. B. A Comprehensive Framework for Classifying the Benefits of ERP Systems. Association for Information Systems Electronic Library (AISeL), Americas Conference on Information Systems (AMCIS) 2000. Journal of Information Management 2003; 23(5); 431-442.

7. Garg, V.K., Venkitakrishnan, N.K. Enterprise Resource Planning: Concepts and Practice Ed. ke-Eastern Economy Edition, PHI Learning Pvt. Ltd. 2004.

8. Olhager, J., Selldin, E. Strategic Choice of Manufacturing Planning and Control Approaches: Empirical Analysis of Drivers and Performance, APMS 2007; 35-42.

9. Lucas, Walton, and Ginzberg , 1988. Implementing packaged software. MIS Quarterly, page 537.

10. Ifenedo 2007. Interactions between organizational size, culture and structure and some IT factors in the context of ERP success assessment, an exploratory investigation. Journal of Computing Information Systems 47(4) page. 28.

11. Huang, Palvia, 2001. ERP implementation issues in advanced and developing countries. Journal of Business Process Management 7(2) page 276.

12. Hitt, Wu, Zhou, 2002. Investment in enterprise resource planning, business impact and productivity measures on Journal of Management Information System 19(1) page 71.

13. Langenwalter, 2000. Enterprise Resource Planning and Beyond Integrating Your Entire Organization. St. LuciePress- Boca Raton, FL.

14. $\mathrm{Qu}$, insonneault, $\mathrm{Oh}$, Influence of industry characteristics on information technology outsourcing, Journal of Management Information Systems 27 (4), 2011, page 99-127.

15. Staehr, Shanks, Seddon, An explanatory framework for achieving business benefits from ERP systems, Journal of the Association for Information Systems 13 (6) 2012 page 424-465.

16. Byrne BM (1998). Structural Equation Modeling with LISREL, PRELIS and SIMPLIS: Basic concepts, applications and programming. Mahwah, New Jersey: Lawrence Erlbaum Associates.

17. Hair JF, Anderson RE, Tatham RL, Black WC, Babin BJ (2006). Multivariate Data Analysis, 6th edn., Pearson Education, New Delhi. 734-735 